\title{
Predicting Stock Price Movements: Regressions versus Economists
}

\author{
Paul Söderlind* \\ First draft: November 2006; Current draft: 24 November 2008 \\ Forthcoming in Applied Financial Economics Letters
}

\begin{abstract}
The forecasting performance of the Livingston survey and traditional prediction models of stock prices is analysed. The survey forecasts look similar to those from a "too large" prediction model: poor out-of-sample performance and too sensitive to recent and irrelevant information.
\end{abstract}

Keywords: Livingston survey, out-of-sample forecasts, overfitting, recency bias

JEL Classification Numbers: G12

\section{Introduction}

This paper studies two aspects of the Livingston survey on predicted equity prices: could this panel of economists predict price changes—and did they believe they could?

Return predictability is one of the most contested areas in financial economics. Recently, Goyal and Welch (2008) argue that the evidence of predictability of equity returns disappears when out-of-sample forecasts are considered. In a reply, Campbell and Thompson (2008) claim that there is still some out-of-sample predictability, provided we put reasonable restrictions on the estimated models.

*University of St. Gallen and CEPR. Address: SBF, University of St. Gallen, Rosenbergstrasse 52, CH9000 St. Gallen, Switzerland. E-mail: Paul.Soderlind@unisg.ch. I thank Paolo Giordani for comments; Jan Bernhard, Michael Fischer and Felix Moldenhauer for help with data. 
The contribution of the current paper is twofold. First, it updates the evidence on the forecasting performance of the Livingston survey to include recent data (see, for instance, Dokko and Edelstein (1989), Bondt (1991) and Pearce (1984)). Second, and more importantly, it relates to recent studies of out-of-sample forecasting and behavioural biases.

It is found that the survey forecasts $(i)$ perform worse than naive forecasts (the historical mean) and small traditional prediction models (regressions on the dividend yield, T-bill rate, etc.) and (ii) share many properties with "too large" prediction models-in particular oversensitivity to recent data.

\section{Data}

Most of the data used in this paper are standard: various S\&P indices, inflation rates, Tbill rates and dates of NBER recessions. ${ }^{1}$ The survey data on predicted future stock index values is somewhat less known, so this section is devoted to presenting and discussing it.

The Livingston semi-annual survey collects forecasts of economists in industry, government, banking and academia. It was started in 1946 by the financial columnist Joseph Livingston, but since 1990 it has been administered by the Federal Reserve Bank of Philadelphia. Since June 1952 the survey has asked about predicted Standard \& Poor (S\&P) index levels 6 and 12 months ahead. For further details, see Federal Reserve Bank of Philadelphia (2004, 2005).

This is a very interesting data set: it gives a long time series of predictions from a group of well informed economists, most of whom are close to the financial markets (for instance, the Livingston panel in December 2006 included, among others, the Chief US Economist of Morgan Stanley and the Chief Economist of Standard\&Poor's). It is very important to have a data set that spans several stock market cycles to mitigate small samples problems. However, there are issues with how to use the data.

In particular, it is tricky to calculate implied forecasts of capital gains (stock price changes) from the survey data. The June and December surveys are sent out in late May and November respectively, and contain base values of the stock index, typically from

\footnotetext{
${ }^{1}$ The data of the Livingston Survey is from the Federal Reserve Bank of Philadelphia (http://www.phil.frb.org/). The monthly S\&P 500 and S\&P Industrials price indices are from S\&P's Trade and Securities Statistics (1976), Compustat and DataStream. The dividends on the S\&P 500 and the inflation rate are from Shiller's homepage (http://www.econ.yale.edu/\%7Eshiller/data.htm), see Shiller (2000). For a discussion of the historical S\&P series, see Jones and Wilson (2002). The 3-month T-bill rate is from FRED II (http://research.stlouisfed.org/fred2/).
} 
mid May/November. It would seem to be straightforward to calculate a forecast of capital gains by dividing the forecasted future level by the base value. Unfortunately, some of the base values are highly unreliable. An alternative approach (used by Pearce (1984)) is to replace the base value with the index level from the last day of the month before the survey. However, it is unclear if the respondents had access to the end-of-month values when filling out the forms.

Unfortunately, the time series pattern on the forecasts of capital gains is sensitive to the choice of base value-and both alternatives produce some strange forecasts. I will therefore combine the 6- and 12-month forecasts to calculate an implied forecast of the growth rate over a 6-month horizon starting 6 months from now (as in Dokko and Edelstein (1989)). To be precise, let $P_{t}$ be the S\&P index in month $t$ and let $\mathcal{E}_{t-s} P_{t}$ be the Livingston forecast in month $t-s$. In this paper, I study if the ex post capital gain $\left(P_{t} / P_{t-6}-1\right)$ is well forecasted by the implied Livingston forecast $\left(\mathcal{E}_{t-12} P_{t} / \mathcal{E}_{t-12} P_{-6}-\right.$ 1) and other variables known in $t .^{2}$ This avoids the problem with the base level and is also likely to mitigate the effect of the slightly different response dates of the survey participants.

I form one combined series of forecasts by using the Livingston survey on S\&P Industrials for the early period (June 1952 to June 1990) and the S\&P 500 for the late period (since December 1990) — and a similar series for the ex post capital gains. To get a familiar scale and reduce potential problems with non-stationarity due to inflation trends, a T-bill rate is subtracted from both series to create "excess capital gains." In practice, this does not change the results much, since both ex post and predicted capital gains are much more volatile than the T-bill rate.

\section{Forecasting Performance}

This section reports the forecasting performance of simple regression models (in-sample and out-of-sample) and of the Livingston survey.

The predicted variable is the 6-month capital gain in excess of a T-bill rate (denoted $r_{t}$ below). The survey forecasts and the traditional predictors (generically denoted $x_{t-12}$ ) are from 12 months earlier.

\footnotetext{
${ }^{2}$ Strictly speaking, we would like to have survey data on the expected capital gain $\mathcal{E}_{t-12}\left(P_{t} / P_{t-6}\right)$, but the survey only contains information on expected index levels. Therefore, $\mathcal{E}_{t-12} P_{t} / \mathcal{E}_{t-12} P_{t-6}$ is used as an approximation.
} 


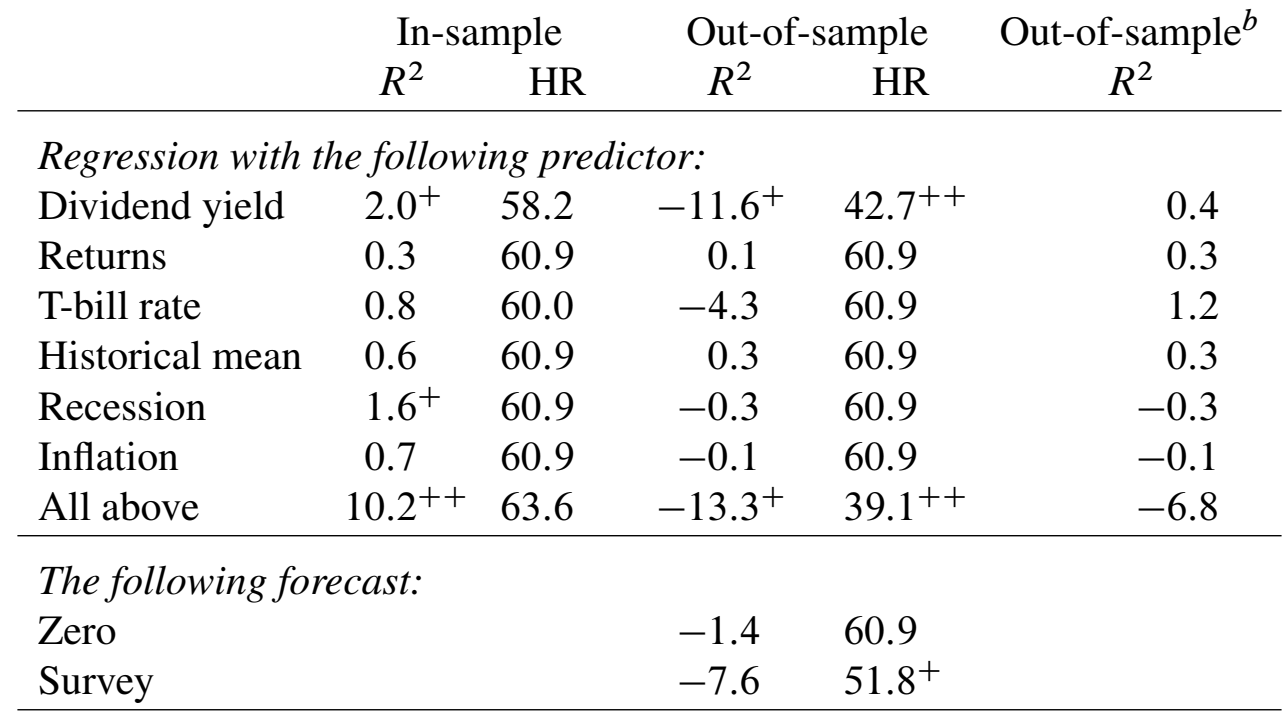

Table 1: $R^{2}$ and hit ratio (HR) from forecasting 6-month excess capital gains with different predictors 1953-2007, \%. The table shows results for the 6-month horizon starting 6 months ahead. The out-of-sample $R^{2}$ is relative to the historical mean. The out-of-sample ${ }^{b}$ restricts all predictions to be non-negative. The hit ratio is the fraction of times that both the prediction and the outcome are non-negative or when they are both negative. ${ }^{+}\left({ }^{++}\right)$indicates significance (relative to the historical mean) at the $20 \%$ (10\%) level. The test for the in-sample $R^{2}$ is a standard test of the regression (that $R^{2}=0$ ), while the other tests are Diebold and Mariano (1995) tests of relative predictive ability (compared to the historical mean).

The first column of Table 1 summarises the in-sample predictability from using prediction equations ( $r_{t}$ regressed on a constant and $x_{t-12}$ ) -in terms of the traditional $R^{2}$. For instance, the first number says that using only the dividend yield as predictor gives an in-sample $R^{2}$ of $2 \%$, which is significant at the $20 \%$ level (indicated by the + sign). The other variables (returns, T-bill rate, the historical mean capital gain calculated on a sample from 1926 to the month before the capital gain, an indicator of NBER recessions and the inflation rate) are all worse. Notice that the historical mean is time-varying (since it estimated recursively) and that it is here used as a predictor in a regression equation, so the forecast is not necessarily the same as the historical mean itself. Using all these predictors at the same time in a multiple regression gives a reasonably high $R^{2}$ of $10.2 \%$-which is the only regression that is significant at the $10 \%$ level. These $R^{2}$ are in line with the typical evidence on financial returns (that is, low), but even this low predictability can have important effects on portfolio choice and performance (see, for instance, Campbell and Thompson (2008)).

The second column of Table 1 shows the "hit ratio," defined as the fraction of time 
that the prediction gets the sign of the capital gain right (with a zero forecast counted as a positive number). This is a useful statistics if the sign of the prediction is used as a buy/sell signal. Most of the predictors get the value $60.9 \%$, which happens to equal the fraction of times the actual capital gain is positive. The simple reason is that these predictors always generate positive forecasts, so they get it right whenever the actual capital gain is positive. Using all predictors in a multiple regression gives just a slightly higher hit ratio, in spite of the relatively good $R^{2}$.

The third column of Table 1 shows the out-of-sample $R^{2}$ (as in Campbell and Thompson (2008)). This measure compares the mean squared errors of the prediction model to using the (recursively estimated) historical average as the forecast: it is negative when the prediction models has a higher mean squared error than the (recursively estimated) historical average. ${ }^{3}$ To calculate the out-of-sample forecasts, the prediction model is estimated on the sample from 1926:1 to period $t-12$, and the observed predictor in $t-12$ is then used to generate a forecast of $r_{t}$. This is repeated for all June and December months from 1952 to 2006- to have exactly the same sample as the Livingston survey.

The results in the third column of Table 1 indicate very little out-of-sample predictability: several variables (including the dividend yield) perform worse than the historical mean (similar to the evidence in Goyal and Welch (2008) and Campbell and Thompson (2008)). It is interesting that the "large" prediction model (using all predictors in a multiple regression) is worst. This is a common finding in the forecasting literature: large models often suffer from in-sample overfitting and therefore have poor out-of-sample performance (see, for instance, Makridakis, Wheelwright, and Hyndman (1998)). The out-of-sample hit ratios in column 4 are still $60.9 \%$ for most predictors, but considerable lower for the dividend yield and the multiple regression (both are significantly worse than than the historical mean at the $10 \%$ significance level).

The last column of Table 1 also shows out-of-sample evidence, but where the predictions are replaced by zero if they are negative. ${ }^{4}$ This improves the performance quite a bit: most predictors get slightly positive out-of-sample $R^{2}$ values (as in Campbell and Thompson (2008)), but the large model using all predictors is still very poor: the $R^{2}$ is

\footnotetext{
${ }^{3}$ The "out-of-sample $R^{2}$ " is $1-\sum_{t=s}^{T}\left(r_{t}-\hat{r}_{t}\right)^{2} / \sum_{t=s}^{T}\left(r_{t}-\bar{r}_{t}\right)^{2}$, where $s$ is the first period with an out-of-sample forecast, $r_{t}$ is the actual value in $t, \hat{r}_{t}$ is the model forecast of the value in $t$ and $\bar{r}_{t}$ is the recursively estimated average value.

${ }^{4}$ Other non-linear restrictions, for instance, using the max of the prediction and the negative of the recent dividend yield, give similar results.
} 
$-6.8 \%$. (No hit ratios are shown for this case, since they are all equal 60.9\%.)

The last two lines of Table 1 report the out-of-sample $R^{2}$ and hit ratios for a zero forecast and the median Livingston survey forecast (see below for details on individual forecast performance). Interestingly, always predicting a zero excess capital gain is not such a terrible idea since the $R^{2}$ is $-1.4 \%$. In contrast, the Livingston survey is really poor: the $R^{2}$ is almost $-8 \%$ and the hit ratio is below $52 \%$ (significantly worse than the historical mean at the $20 \%$ level). This confirms results on earlier samples (for instance, in Bondt (1991)), that professional forecasters typically fail to predict financial markets.

It can also be shown (not reported in the table) that a classical test of forecast unbiasedness (regressing the ex post values on a constant and the forecasts) gives an annualised intercept around $3.5 \%$ and a slope coefficient of -0.1 . The coefficients are significantly (at the 5\% level) different from 0 and 1 respectively. This means that the survey forecasts underestimated the average ex post capital gain and actually moved inversely with the ex post data. ${ }^{5}$

To summarise, the Livingston survey is a much worse forecaster than most traditional one-variable prediction equations (out-of-sample) — and it is almost as bad as a typical "too large" forecasting model (as the regression using all predictors simultaneously). Since I am using the median forecast from the survey, this should be considered as an upper boundary of the forecasting performance of a randomly picked survey participant. ${ }^{6}$

As a robustness check, Figure 1 shows the time profile of the out-of-sample predictability. The figure plots the out-of-sample $R^{2}$ for recursive samples (the last sample is for 1953-2007 and thus coincides with the third column in Table 1). Most of the traditional predictors have a fairly even (and non-impressive) performance over time. Predicting zero was a bad idea during the 1950s, but a good one 1965-1975, and as good as using the historical mean thereafter. The survey forecasts were poor for most of the period, except the late 1960s to the early 1980s. Overall, the general impression from Figure 1 is that none of the prediction models outperform the historical mean for an extended period of time. The evidence of weak forecasting performance reported earlier is therefore reasonably robust across subsamples.

\footnotetext{
${ }^{5}$ In contrast, Dokko and Edelstein (1989) find that the survey is unbiased in the subsample 1955-1985.

${ }^{6}$ There is good theoretical and empirical evidence that combining (averaging) forecasts typically reduces the forecast error variance (see, for instance, Bates and Granger (1969)).
} 

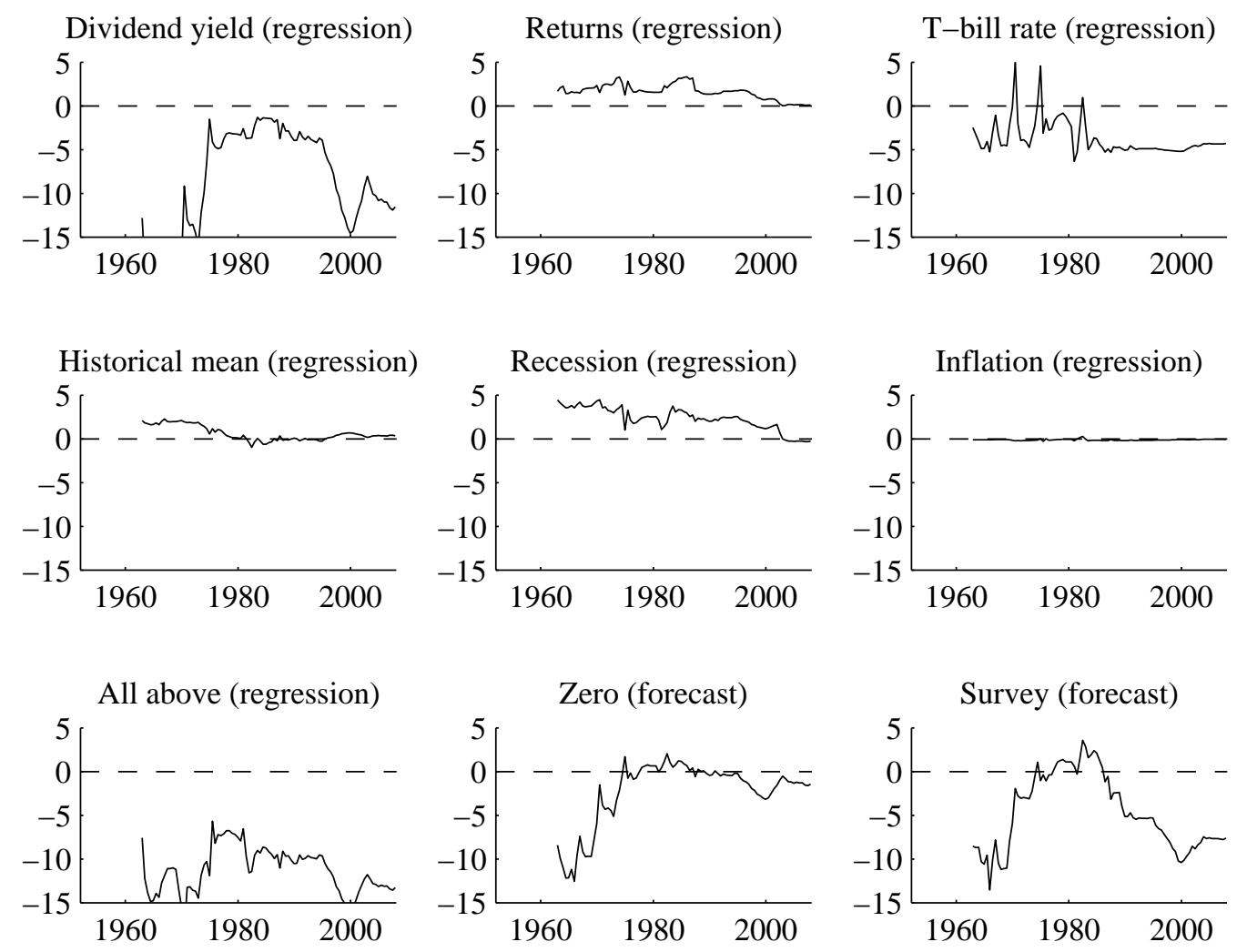

Figure 1: Recursive out-of-sample $R^{2}$ from forecasting 6-month excess capital gains with different models, \%. This figure shows the out-of-sample $R^{2}$ for samples that start in 1952 and end in the period marked on the horisontal axis. The first sample of ex post data is 1953.6-1961.12 and the last sample is $1953.6-2007.12$.

As a second robustness check, I repeat the analysis of the Livingston survey by studying the individual forecast performance. That is, I calculate an out-of-sample $R^{2}$ for each forecaster by comparing with the performance of the historical mean-for just those dates the forecaster participated in the survey. The results show a wide dispersion of the $R^{2}$ for the 382 forecasters that participated at least once during the sample period. However, the median $R^{2}$ is -0.25 , which is clearly lower than for the median forecast-indicating that pooling forecasts is useful also for the Livingston survey. Comparing across forecasters' affiliation shows that most sectors (non-financial business, academic, commercial banking) have median $R^{2}$ s between -0.2 and -0.3 . (Interestingly, investment banking has a median of -0.42 .) Overall, this suggests that the previously reported results are indeed an upper boundary of the forecasting performance of most Livingston participants. 


\section{Characterising the Survey Forecasts}

This section studies the relation between the survey forecasts and traditional predictors.

Figure 2 shows the median survey predictions and also the NBER recessions marked by shaded areas (disregard the dotted curve for now). The Livingston forecasters clearly did not believe in the random walk hypothesis: there are distinct movements in the forecasts. In particular, the forecasts have local maxima in almost all recessions. This fits well with the correlations reported in the first column of Table 2: the survey forecast is negatively correlated $(-18.3 \%)$ with current ex post returns (over the last 6 months), and strongly positively correlated $(30.6 \%)$ with a dummy variable for NBER recessions. ${ }^{7}$ In short, the Livingston forecasts manifest a belief in medium-term mean-reversion (recall, the forecast is for the development over months 7-12).

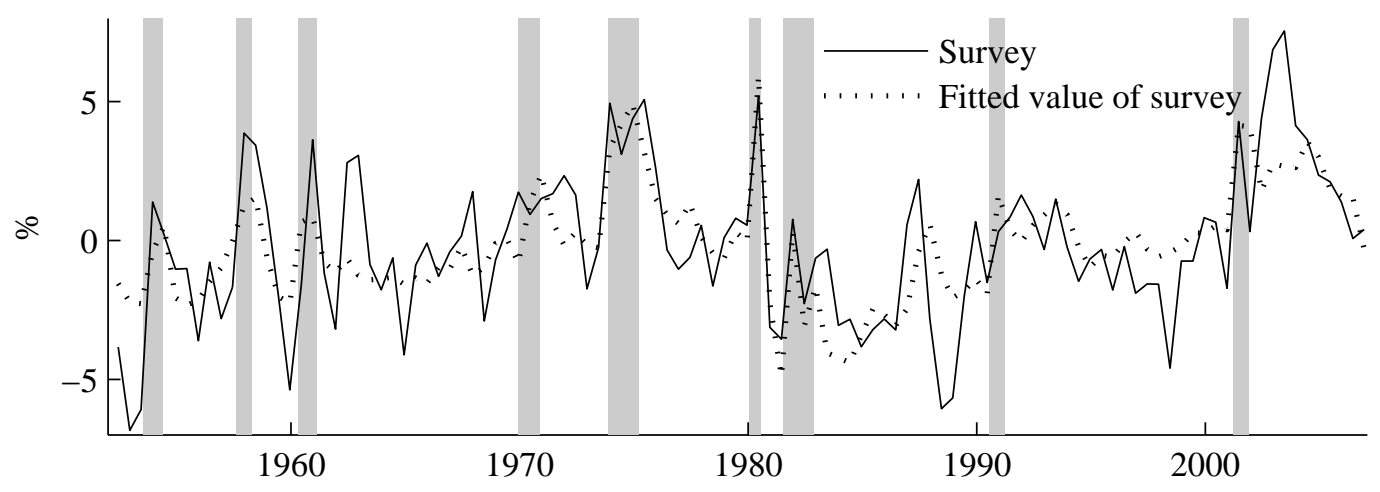

Figure 2: Expected excess capital gains on the combined S\&P index, \%. This figure shows the survey predictions of the capital gains on the S\&P index (in excess of a T-bill rate) for the 6-month horizon starting 6 months ahead, their fitted values from a regression on traditional predictors and the NBER recessions (shaded areas).

The survey forecasts are also strongly related to traditional predictors. For instance, most of the correlations with the survey forecasts in Table 2 are significant at the $10 \%$ level (actually, even at the 5\% level), whereas none of the correlations with the ex post capital gains are.

It can be shown (not reported in the table) that regressing the survey forecasts (or the survey forecasts minus the recursively estimated historical mean) on all the predictors

\footnotetext{
${ }^{7}$ Bacchetta, Mertens, and van Wincoop (2008) also find a negative correlation between survey expectations and the dividend yield (using the UBS/Gallup poll 1998-2003), but a positive correlation with an interest rate.
} 
gives an $R^{2}$ above $50 \%$. This is illustrated by the dotted line in Figure 2, which shows the fitted values from that regression: the survey forecasts seem strongly related to traditional predictors. Two conclusions are immediate. First, despite claims to the contrary, it does not seem too hard to understand/explain "market beliefs" about the equity market. Second, the poor performance of the survey forecasts is, to a large extent, due to the oversensitivity to recent information-which all have little or no forecasting power (as discussed before). This is also supported by the evidence from a regression based test of encompassing (see, for instance Diebold (1988)) where the ex post data is regressed on the (recursively estimated) historical mean and the survey forecasts. The results (not reported) indicate that the survey has a coefficient that is virtually zero, while the historical mean has a sizeable and significant coefficient.

This strengthens the impression from the analysis of the forecast performance: the Livingston survey forecasts seem to be generated by a "too large" forecasting model that reacts to recent, but irrelevant, information. In other words, the forecasters use forecasting models that suffer from overfitting and recency bias (see, for instance, Bondt and Thaler $(1985,1990))$.

\begin{tabular}{lcc} 
& Survey forecasts & Ex post \\
\hline Dividend yield & $-21.3^{++}$ & $14.3^{+}$ \\
Returns & $-18.3^{++}$ & -5.2 \\
T-bill rate & $-21.9^{++}$ & -8.7 \\
Historical mean & -8.9 & -7.8 \\
Recession & $30.6^{++}$ & $12.8^{+}$ \\
Inflation & $22.3^{++}$ & -8.5 \\
\hline
\end{tabular}

Table 2: Correlations, \%. The survey forecasts and the ex post data are for the capital gain over a 6-month horizon starting 6 months ahead. ${ }^{+}\left({ }^{++}\right)$indicates significance at the $20 \%(10 \%)$ level, according to a GMM-based test.

\section{Conclusion}

This paper analyses the forecasts of equity price changes in the Livingston survey for the sample from 1953 to 2007 . The results indicate that the survey forecasts perform clearly worse than the historical mean (estimated on a recursive sample), and that they share many properties with "too large" prediction models. 
There are two implications of this finding. First, if this group of forecasters cannot predict stock price changes, then we should perhaps be sceptical of the small set of (carefully selected) regressions that can. Maybe they are just type 1 errors? If so, portfolio recommendations should not rely on predictability. Second, it still be seems as if the forecasters think they can predict price changes: the forecasts have considerable timevariation - and they are strongly correlated with traditional (failing) predictors. Maybe studies of portfolio choice and asset pricing (in contrast to portfolio recommendations) should incorporate beliefs of time-varying expected stock price movements.

\section{References}

Bacchetta, P., E. Mertens, and E. van Wincoop, 2008, "Predictability in financial markets: what do survey expectations tell us?," Journal of International Money and Finance, forthcoming.

Bates, J. M., and C. W. J. Granger, 1969, "The combination of forecasts," Operations Research Quarterly, 20, 451-468.

Bondt, W. F. M. D., 1991, "What do economists know about the stock market?, Journal of Portfolio Management, 17, 84-91.

Bondt, W. F. M. D., and R. H. Thaler, 1985, “Does the stock market overreact?," Journal of Finance, 40, 793-805.

Bondt, W. F. M. D., and R. H. Thaler, 1990, “Do security analysts overreact?," American Economic Review, 80, 52-57.

Campbell, J. Y., and S. B. Thompson, 2008, "Predicting the equity premium out of sample: can anything beat the historical average," Review of Financial Studies, 21, 15091531.

Diebold, F. X., 1988, "Serial correlation and the combination of forecasts," Journal of Business and Economic Statistics, 6, 105-111.

Diebold, F. X., and R. S. Mariano, 1995, “Comparing predcitve accuracy," Journal of Business and Economic Statistics, 13, 253-265. 
Dokko, Y., and R. H. Edelstein, 1989, "How well do economists forecast stock market prices? A study of the Livingston surveys," The American Economic Review, 79, 865871.

Federal Reserve Bank of Philadelphia, 2004, "Documentation for the discontinued stock price forecasts in the Federal Reserve Bank of Philadelphia's Livingston Survey," http://www.philadelphiafed.org/econ/liv/S\&P.html.

Federal Reserve Bank of Philadelphia, 2005, "Livingston Survey documentation," http://www.philadelphiafed.org/econ/liv/index.html.

Goyal, A., and I. Welch, 2008, "A comprehensive look at the empirical performance of equity premium prediction," Review of Financial Studies 2008, 21, 1455-1508.

Jones, C. P., and J. Wilson, 2002, “An analysis of the S\&P 500 index and Cowles's extensions: price indexes and stock returns 1870-1999," Journal of Business, 75, 505-533.

Makridakis, S., S. C. Wheelwright, and R. J. Hyndman, 1998, Forecasting: methods and applications, Wiley, New York, 3rd edn.

Pearce, D. K., 1984, “An empirical analysis of expected stock price movements," Journal of Money, Credit and Banking, 16, 317-327.

Shiller, R. J., 2000, Irrational exuberance, Princeton University Press, data available at http://www.econ.yale.edu/ shiller/data.htm. 